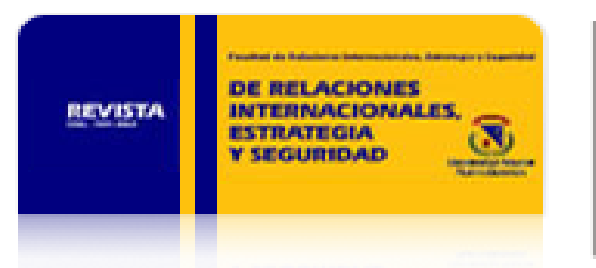

Revista de Relaciones Internacionales, Estrategia y Seguridad

ISSN: 1909-3063

cinuv.relinternal@unimilitar.edu.co

Universidad Militar Nueva Granada

Colombia

Sánchez Cabarcas, Fabio

COLOMBIA: CONFLICTO IRREGULAR, DESPLAZAMIENTO INTERNO Y SEGURIDAD HUMANA

Revista de Relaciones Internacionales, Estrategia y Seguridad, vol. 4, núm. 1, enero-junio, 2009, pp.

159-172

Universidad Militar Nueva Granada

Bogotá, Colombia

Disponible en: http://www.redalyc.org/articulo.oa?id=92712970009

- Cómo citar el artículo

- Número completo

- Más información del artículo

- Página de la revista en redalyc.org

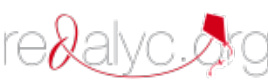

Sistema de Información Científica

Red de Revistas Científicas de América Latina, el Caribe, España y Portugal

Proyecto académico sin fines de lucro, desarrollado bajo la iniciativa de acceso abierto 
rev.relac.int.estrateg.segur.4(1):159-172,2009

\title{
COLOMBIA: CONFLICTO IRREGULAR, DESPLAZAMIENTO INTERNO Y SEGURIDAD HUMANA
}

\author{
Fabio Sánchez Cabarcas*
}

\section{RESUMEN}

Este trabajo tiene como propósito analizar el desplazamiento forzado interno, como una de las consecuencias de la guerra irregular moderna. En la primera parte, se hace una descripción histórica de la evolución del conflicto irregular interno colombiano. Luego se expone el gran desafío que implica distinguir a la insurgencia de la población civil. Finalmente, se analiza el desplazamiento forzado interno, a partir de la política de seguridad humana de Kaldor.

Palabras clave: guerra irregular, conflicto, insurgencia, estrategia, desplazamiento forzado interno, seguridad humana

\footnotetext{
* Comunicador Social-Periodista, PUJ, Magíster en Relaciones Internacionales, PUJ. Candidato a doctor en Relaciones Internacionales, Universidad Autónoma de Barcelona. Profesor de tiempo completo, Escuela de Política y Relaciones Internacionales, Universidad Sergio Arboleda, Bogotá. fabiob.sanchez@usa.edu.co
} 


\begin{abstract}
The main purpose of this paper is to analyze forced internal displacement as a consequence of modern domestic irregular war. The first part contains a historical description of the Colombian irregular internal conflict. It continues with a challenge that implies the distinction between insurgent elements and the civilian population. Finally, from Kaldor's human security perspective, the article analyzes forced internal displacement in Colombia.
\end{abstract}

Key words: irregular war, conflicts, insurgency, strategy, forced internal displacement, human security

Analizar el conflicto colombiano desde perspectivas diferentes siempre es un reto. En este trabajo intento destacar algunas particularidades del mismo: sus antecedentes, su condición de guerra irregular y, una de sus principales consecuencias: el desplazamiento forzado interno, pero esta vez analizado desde la política de la seguridad humana, un concepto en el cual ha profundizado Kaldor $y$, el cual permite, revisar las consecuencias de un conflicto interno irregular que se desarrolla en medio de una violencia informal organizada.

En la primera parte elaboro una breve descripción histórica del conflicto colombiano, posteriormente, explico las características de la guerra irregular y la dificultad persistente en distinguir insurgentes de población civil. Finalmente, analizo el desplazamiento forzado interno desde la óptica de la política de la seguridad humana, acompañado de unas conclusiones finales.

\title{
EL CONFLICTO COLOMBIANO: ANTECEDENTES
}

El conflicto colombiano representa un tema agudo en el estudio de las relaciones internacionales contemporáneas. No existe precisión acerca de su definición: algunos hablan de un conflicto irregular intraestatal, y otros debaten si se trata de una guerra civil o no. ${ }^{1}$ También se estudia la posibilidad de un estado fallido que incluso puede desestabilizar a la región andina, ${ }^{2}$ pero al revisar en detalle algunas particularidades, el país presenta una lógica de violencia organizada, concepto acuñado hace unos años por la teórica Mary Kaldor. ${ }^{3}$ A pesar de ser evaluado durante décadas como un país riesgoso, nunca ha dejado de atraer inversión extranjera y, además, posee legitimidad nacional e internacional porque se encuentra en un equilibrio que no lo lleva al extremo del caos total. No obstante y, como veremos a continuación, los desplazados internos son las principales

\footnotetext{
${ }^{1}$ Nye 2003, 38. Para un debate sobre si es guerra civil el conflicto colombiano más adelante veremos el debate entre Nasi, Ramírez y, Lair 2003.

2 Shifter et al. 2000, 24. En este informe manifiestan la situación deteriorada de Perú, Venezuela, Ecuador, Panamá, y Brasil, a causa del conflicto colombiano. Ver también, Pizarro y Bejarano 2003.

${ }^{3}$ Kaldor 2001.

COLOMBIA: CONFLICTO IRREGULAR, DESPLAZAMIENTO INTERNO Y SEGURIDAD HUMANA
} 
víctimas: una gran cantidad de ciudadanos que se encuentran en medio de actores armados al igual que en el resto de guerras irregulares modernas que se presentan en África y Asia.

Para Fearon y Laitin, los factores que explican los riesgos o existencia de una guerra civil no son las características étnicas o religiosas de ésta. Son más importantes las condiciones que favorecen la insurgencia, como por ejemplo la pobreza, la cual marca financiera y burocráticamente a los estados débiles y también favorece el reclutamiento de rebeldes, la inestabilidad política, el terreno geográfico complejo y la población numerosa, variables todas que se cumplen en Colombia, y que como se verá más adelante marcarán el desarrollo histórico y conflictivo del país. ${ }^{4}$ Algunos académicos en Colombia manifiestan que efectivamente sí se trata de una guerra civil, ${ }^{5}$ no obstante definirla como un conflicto interno e irregular, puede ser más preciso y se aproxima a lo expuesto por John A. Vásquez, uno de los teóricos más reconocidos en estudio de conflictos en el área de las relaciones internacionales, quien manifiesta: «La mayoría de las guerras han ocurrido en órdenes políticos y no son peleadas en condiciones de anarquía, es dentro de un orden regional o global que se regula o modela la forma en cómo se lucha y se contiene» ${ }^{6}$ (traducción propia).

El conflicto colombiano tiene antecedentes históricos que obedecen a disputas bipartidistas entre liberales y conservadores. La Guerra de los Mil Días (1899-1902) y el período conocido como La Violencia (19481960) son considerados como guerras civiles que ocasionaron miles de muertos y que desde entonces han

\footnotetext{
${ }^{4}$ Fearon y Laitin 2003, p. 88.

${ }^{5}$ Nasi, Ramírez, Lair 2003, p. 119-124. A continuación sus definiciones:
}

Nasi al respecto: «El conflicto armado colombiano sí puede considerarse como una 'guerra civil'. [...] En los noventa, Peter Wallenstein y otros investigadores empezaron a utilizar el término 'guerra civil' para toda confrontación armada dentro de un Estado que produce al menos mil muertes relacionadas con el combate, por año. [...] Bajo esta acepción, desde mediados de los ochenta, Colombia representa una clara instancia de guerra civil, dado que el número de muertes producidas por el conflicto armado ha oscilado entre mil y poco más de tres mil quinientas por año». Por su parte Ramírez: «El conflicto colombiano puede definirse como una guerra civil, si se tiene en cuenta que sus actores armados son unos actores sociales y políticos. Tanto las guerrillas de derecha e izquierda como la fuerza pública son portadoras de visiones y creencias diferentes acerca del Estado y de las relaciones de este con la sociedad civil, lo cual hace de sus combatientes representantes de una ideología de guerra soportada por intereses colectivos». Y, finalmente Lair: «Desde la segunda mitad de los años noventa, se ha planteado con vigor el debate que consiste en saber si Colombia vive una 'guerra civil'. En una acepción genérica, podemos considerar que la sociedad colombiana experimenta una 'guerra civil' por cuanto ciudadanos procedentes de una misma comunidad política organizada (civitas) han tomado las armas para enfrentarse entre sí y con el Estado. Por lo tanto, si se procura caracterizar la confrontación armada colombiana bajo el calificativo de 'guerra civil', siguiendo un enfoque genérico ya señalado, cabe agregar que se trata de una 'guerra civil' eminentemente privatizada en sus actores, representaciones e intereses, la cual no ha logrado crear las condiciones de una movilización popular estable de gran magnitud a favor de los beligerantes ('guerra civil' parcial o forzada para la población). También, se puede acudir a otra noción que nos parece más adecuada y cercana a la naturaleza del conflicto, a saber 'la guerra contra los civiles'».

${ }^{6}$ Vásquez 1993, p. 268. 
delineado el destino conflictivo de la nación. ${ }^{7}$ A partir de este momento, el país estuvo sumergido en una lógica de violencia bipartidista, que generó disputas entre los sectores menos favorecidos de la sociedad colombiana sobretodo en zonas rurales en donde los niveles de educación eran y, continúan siendo, bajos y deficientes, la distribución de la tierra era inequitativa, al igual que la distribución de los ingresos.

Esta violencia bipartidista culminó con el pacto político entre liberales y conservadores, conocido como el Frente Nacional, ${ }^{8}$ el cual consistió en alternar el poder cada cuatro años, durante 16 años. Si bien esta decisión detuvo los enfrentamientos, en cierta medida, también fue nefasta para la democracia del país, porque aunque sólo vetaba al partido comunista, ${ }^{9}$ no daba juego político a opciones alternativas, que más tarde se convertirían en la bandera de lucha de movimientos guerrilleros de izquierda como las FARC (Fuerzas Armadas Revolucionarias de Colombia), ELN (Ejército de Liberación Nacional) y, EPL (Ejército Popular de Liberación).

No obstante, algunos grupos armados como las FARC se fortalecieron durante el Frente Nacional y se alinearon con ideas socialistas-comunistas. A finales de la década de 1970, con el auge del narcotráfico estas organizaciones se convirtieron en grupos al margen de la ley muy poderosos, por la capacidad de compra de armas que tenían con el dinero de la droga. ${ }^{10}$ Esta escalada de poder de las FARC ocasionó que algunos habitantes de las zonas del Magdalena Medio, Costa Atlántica y Antioquia organizaran cuerpos paramilitares para defender sus predios de los ataques de la guerriIla, dichos grupos fueron entrenados por mercenarios extranjeros, lo cual elevó su capacidad táctica para empezar a enfrentar a su enemigo. ${ }^{11}$ A mediados de la década de 1980 los grupos paramilitares se convirtieron en organizaciones independientes y poderosas, como por ejemplo, las AUC (Autodefensas Unidas de Colombia) las cuales empezaron una lucha territorial con la guerriIla por el control de zonas y corredores para el tráfico de drogas,,$^{12}$ elevando el desplazamiento forzado interno en el país, que ya había iniciado desde la época de La Violencia.

\footnotetext{
${ }^{7}$ Ferreyra y Segura 2000, p. 27. Para estas autoras la cifra de muertos del período conocido como La Violencia es de 160.000, otros autores hablan de 250.000 o hasta 300.000 muertos.

${ }^{8}$ La Declaración de Benidorm (24 de julio de 1956) y el Pacto de Sitges (20 de julio de 1957) fueron firmadas por Alberto Lleras líder del partido liberal y Laureano Gómez, del conservador.

${ }^{9}$ Curiosamente en el país estuvieron las «Brigadas de Paz» conformadas por jóvenes estadounidenses que enseñaban técnicas agrícolas para el desarrollo y modernidad al campo colombiano, algunas fuentes indican que uno de sus propósitos era hallar focos de comunismo en el país.

${ }^{10}$ Fearon y Latin 2003, p. 75 Estos autores manifiestan que la guerra de insurgencia se une a diversas agendas políticas, motivaciones y agravios. En un principio la lucha estaba ligada al comunismo, pero este método ha servido a fundamentalistas islámicos, nacionalistas étnicos o (rebeldes) que se enfocan en el tráfico de drogas (FARC en Colombia) o diamantes (Sierra Leona, como por ejemplo el Consejo Revolucionario de las Fuerzas Armadas, dirigido por Johnny Paul Koroma, quien protagonizó un golpe de estado en 1997).

${ }^{11}$ El mercenario israelí Yair Klein entrenó los primeros escuadrones paramilitares del Magdalena Medio a mediados de la década de 1980. Meses atrás Klein fue detenido en Rusia, donde fue capturado por la INTERPOL. El gobierno colombiano solicitó su extradición. Varios analistas creen que la información que pueda aportar es vital para investigar el origen y consolidación del paramilitarismo en el país.
}

${ }^{12}$ Nuevo Arco Iris 2004, p. 11.

COLOMBIA: CONFLICTO IRREGULAR, DESPLAZAMIENTO INTERNO Y SEGURIDAD HUMANA 
Debe tenerse en cuenta que la migración campesina no sólo fue ocasionada por el conflicto entre diferentes facciones armadas, es importante destacar la ausencia de elementos estatales claves en algunas zonas rurales, como por ejemplo, los precarios sistemas de educación, salud y, una limitada infraestructura. Lo anterior elevó el desempleo y facilitó que los diversos actores armados ilegales Ilenaran esos vacíos institucionales, e impusieran sus propias leyes e injusticias, valiéndose de los elementos y estrategias que caracterizan a las nuevas guerras de la violencia transnacional organizada.

\section{LAS DIFICULTADES DE LA GUERRA IRREGULAR}

La falta de recursos y asistencia social en grandes extensiones de territorio, ha facilitado que tanto grupos guerrilleros como paramilitares, operen con relativa facilidad en algunas zonas del país. En estas zonas, la economía se ha estancado y han crecido el delito, corrupción y crimen organizado, en medio de una lógica en donde se desvanece la diferencia entre quien tiene legalidad y quien la ejerce mediante la fuerza. Este tipo de violencia es nueva, no tiene mucho en común con la violencia bipartidista de principio y mitad del siglo XX, es una violencia "organizada»" ${ }^{13}$ más extendida y menos extrema, pero que genera un drama humano profundo y complejo para la población civil.

En este tipo de conflicto la asimetría entre el estado y las fuerzas irregulares se diluye, porque se utilizan tácticas de guerra de guerrillas (FARC y ELN) y técnicas de contrainsurgencia (paramilitares) que tienen como propósito: desestabilizar las zonas mediante diversos métodos como matanzas masivas, reasentamientos forzosos y una serie de técnicas políticas, psicológicas y económicas de intimidación. ${ }^{14}$ Este tipo de técnicas ha generado un aumento espectacular en el número de desplazados internos en el país, confirmando la tesis de Kaldor que sostiene que la mayor parte de la violencia en los conflictos modernos, está dirigida contra civiles. Al iniciar el siglo XX las proporción entre bajas militares y civiles era de 8:1 ahora se ha invertido a 1:8, lo cual se puede confirmar con la cifra de desplazados internos que tiene Colombia, que para octubre de 2005 alcanzó los 3.7 millones, en febrero de 2006 estaba en 1.8 millones, ${ }^{15}$ y ahora oscila entre 2 y 3 millones. No obstante la cifra se podría ajustar más.

En la mitad del siglo XX en Colombia, luego de La Violencia, surgieron grupos como las FARC, ELN, EPL, cuya táctica se inspiraba en los postulados de "guerra de guerrillas» de Mao Zedong y Ernesto "Che» Guevara. Teoría en la que prima ganar el apoyo de la población, inmiscuirse en esta y evitar el contacto directo con las fuerzas tradicionales, en palabras de Mao, el pueblo debería ser

\footnotetext{
${ }^{13}$ Kaldor 2001, p. 18.

14 Ibíd., p. 23.

${ }^{15}$ Cirera 2006, p. 16.

${ }^{16}$ Kaldor 2001, p. 23.
} 
el mar y el guerrillero «un pez en el agua». ${ }^{16}$ Según esto, los revolucionarios intentaban crear zonas modelo para ganar la simpatía de la gente, pero a partir de la década de 1980 estos grupos dejaron de lado el idealismo revolucionario para convertirse en controladores políticos de algunas zonas mediante la fuerza. Así, interferían en las elecciones democráticas, favoreciendo a líderes de su interés, seleccionando así a la población que les apoyaba y, eliminando a sus posibles opositores. ${ }^{17}$ El problema que esto generó fue una respuesta paramilitar con tácticas de contrainsurgencia para «envenenar» $\mathrm{o}$ "drenar» el mar del que hablaba Mao. ${ }^{18}$ Pero derrotar de forma directa y rápida a una guerrilla es muy difícil porque esta evita el contacto directo con sus oponentes mediante campañas estilo "golpear-huir». La respuesta paramilitar a esta dificultad ha sido elegir como objetivo a la población que es, según estos, la base de la guerrilla, un tipo de estrategia que conlleva al asesinato intencional de un masivo número de civiles. ${ }^{19}$

Downes calcula que en los pasados tres siglos los civiles han constituido un cuarto de las muertes de todas las guerras. En el siglo XX estima que murieron 50 millones de no combatientes, ${ }^{20}$ es decir el $60 \%$ de las muertes en guerra en los últimos 100 años. ${ }^{21}$ Las anteriores cifras indican que tanto los gobiernos como otros actores armados han olvidado las prescripciones legales y normativas contempladas en el Derecho Internacional Humanitario (DIH) que prohíben convertir en objetivos a los no combatientes, pero de forma curiosa y preocupante algunos estudios demuestran que las democracias que se han adherido a principios y normas liberales que prohíben el asesinato de civiles, desarrollan una tendencia a atacar a no combatientes, debido a la vulnerabilidad de sus líderes ante la opinión pública, que les exige resultados y hace que estos incurran en costos elevados en el campo de batalla, por miedo a perder el apoyo, ${ }^{22}$ más aún, cuando en la mayoría de los casos las críticas y sanciones a los posibles abusos son de tipo moral y sólo mancillan la reputación del estado. ${ }^{23}$ En este sentido, el teórico Stathis Kalyvas, luego de revisar la guerra de independencia de Argelia, manifestó que había una tendencia de los teóricos en Occidente a negar las masacres contra civiles y que, simplemente, habían asumido que esta clase de violencia era irracional o dirigida por el sadismo o frenesí de la batalla. ${ }^{24}$

\footnotetext{
17 Ibíd., p. 129.
}

${ }^{18}$ Kaldor sostiene que la contrainsurgencia fracasó en Vietnam, pero continuó recibiendo el apoyo de gobiernos occidentales para derrocar gobierno de izquierda durante la Guerra Fría. Es el caso del RENAMO en Mazambique, los Muyahiddin en Afganistán y la Contra en Nicaragua, la conclusión de esta autora es que la guerra convencional ya no es una opción viable y por lo tanto se recurre a métodos atroces contra la población civil.

${ }^{19}$ Valentino 2004, p. 377.

${ }^{20}$ Definición de no combatiente: «Una persona que no es miembro de guerrilla o grupo militar y que no participa activamente en hostilidades que intenten causar daño físico al enemigo personal o a su propiedad. Derecho Internacional Humanitario (Convenios de Ginebra 1949 y Protocolos adicionales 1977).

${ }^{21}$ Downes 2006, p. 152.

${ }^{22}$ Valentino 2004.

${ }^{23}$ Downes 2006, p. 167.

${ }^{24}$ Kalyvas 1999. Citado en Valentino 2004, p. 376. 
Tal y como argumenta Valentino, la lógica de la guerra de guerrillas ha llevado en ocasiones a los líderes a concluir que el asesinato masivo de civiles puede ser una sangrienta pero decisiva solución a la aparentemente intratable y difícil situación que implica una guerra de guerrillas. ${ }^{25}$ Suele ser una táctica temprana porque los civiles son fáciles de atacar, esto genera dividendos inmediatos para los líderes y, en ocasiones, se reducen las amenazas de rebelión y subversión. ${ }^{26}$ De la misma manera, los asesinatos en masa durante le guerra pueden ser una estrategia calculada para superar las dificultades asociadas con el combate de la insurgencia guerrillera, es decir, que se puede considerar el asesinato en masa, como especie de guerra por otro medios. ${ }^{27}$

La lógica de la victimización de civiles es más frecuente en las tácticas de contrainsurgencia, porque lo que se busca es cortar el apoyo de algunos sectores de la población a la guerrilla. Downes expresa que existen dos maneras para lograr este propósito: la primera consiste en disuadir a la gente para que deje de ayudar a los insurgentes desplazando a la población hacia áreas en donde no pueden operar y, en ocasiones, asesinando a colaboradores sospechosos para generar miedo en los demás; la segunda forma es el método de interdicción que concentra a las personas bajo el control del gobierno o simplemente se aniquila a la mayoría quedando rendidos y sin la posibilidad de apoyar a la guerrilla. ${ }^{28}$ En este sentido es importante destacar el señalamiento que hace Valentino sobre el asesinato en masa o victimización civil. Según él, no están limitados a métodos directos de asesinato como ejecución, gases o bombardeos, sino que también incluye muertes causadas por hambre, enfermedades adquiridas durante reubicación y trabajos forzados, confiscación intencional y bloqueo de las necesidades básicas; ${ }^{29}$ esto último tiene estrecha relación con la lógica de violencia organizada en las nuevas guerras que describe Kaldor.

Cabe considerar que una efectiva contrainsurgencia requiere que las fuerzas del gobierno distingan rebeldes «activos» de «no combatientes», sin destruir la vida ni las condiciones que se le permiten a estos últimos. ${ }^{30}$ Este es un problema político, militar y organizacional complejo, aún para militares entrenados de alto nivel como lo son los miembros del ejército colombiano. En la historia hay ejemplos de cómo tropas expertas fracasaron y cometieron excesos en la lucha contrainsurgente: EE.UU. en Vietnam, Gran Bretaña en Irlanda del Norte, URSS en Afganistán. Otro aspecto complejo es que los estados no pueden, en ocasiones, controlar los abusos de poder (botín y pillaje), y esta es una práctica que prolonga más el apoyo a la insurgencia en la población. ${ }^{31}$

\footnotetext{
${ }^{25}$ Valentino 2004, p. 348.

${ }^{26}$ Downes 2006, p. 168.

${ }^{27}$ Valentino Op. Cit., p. 402.

${ }^{28}$ Downes 2006, p. 163.

${ }^{29}$ Valentino Op. Cit., 16 Citado en Downes, p. 156.

${ }^{30}$ Fearon y Laitin 2003, p. 80.

${ }^{31}$ Ibíd., p. 80.
} 
Como puede verse, el conflicto colombiano obedece a una lógica de exclusión social histórica ocasionada por un bipartidismo que generó violencia y facilitó el surgimiento de grupos al margen de la ley. Estos, desde la década de 1980, se han fortalecido con el dinero producto del narcotráfico y por las facilidades que ofrece el mercado negro de armas globalizado. Lo anterior ha generado graves consecuencias en la población civil inocente, en medio de una lucha de insurgencia/ contrainsurgencia, ubicando al país en el segundo lugar con el mayor número de desplazados internos en el mundo después de Sudán. Se trata de un conflicto interno irregular, en el que el gobierno mantiene legitimidad y orden estatal, que no permite acciones de intervención humanitaria como las que se han Ilevado a cabo en Bosnia, Kosovo o Timor Oriental. Es un conflicto que esconde un gran drama humano que veremos a continuación: el desplazamiento forzado interno.

\section{DESPLAZAMIENTO FORZADO INTERNO: VISTO DESDE LA POLÍTICA DE LA SEGURIDAD HUMANA}

Para analizar el desplazamiento forzado interno en Colombia de una manera más adecuada, se deben aclarar primero unos aspectos de lo que implica la seguridad humana en la actualidad..$^{32} \mathrm{La}$ seguridad en ocasiones sigue siendo concebida como la ausencia de violencia física, mientras que el desarrollo es percibido como algo material que mejora la calidad de vida. De la misma forma, los derechos humanos son vistos en ocasiones como derechos civiles y políticos y la sugerencia es que deberían incluirse también derechos sociales y económicos. ${ }^{33}$ Sólo si los conceptos de derechos humanos, seguridad humana y desarrollo humano incluyen derechos sociales, económicos, civiles, políticos y materiales, puede hablarse de un concepto más adecuado de seguridad en la avanzada fase de globalización que vive el mundo en la actualidad.

En las guerras contemporáneas, sobre todo las del Tercer Mundo, sólo una minoría de muertes ocurre en el campo de batalla. La mayoría de personas mueren por la violencia deliberada contra objetivos civiles como resultado de campañas de terror, limpieza étnica, genocidios, minas antipersonales y armas ligeras. Pero también por la falta de acceso a la atención de la salud, enfermedades, hambre y falta de albergue. Por lo tanto, la inseguridad humana no implica sólo el impacto de la violencia armada, también tiene que ver con las violaciones de derechos humanos descritas anteriormente y las consecuencias materiales del conflicto. ${ }^{34}$

Según lo anterior, el indicador que más se acerca a una medida de seguridad humana es el de las personas desplazadas, debido a que éstas constituyen un rasgo típico de las crisis contemporáneas,

\footnotetext{
${ }^{32}$ El concepto de seguridad ha evolucionado en el estudio de las Relaciones Internacionales desde el fin de la Guerra Fría. Varios académicos como David Baldwin y Mohammed Ayoob, coinciden en que se debe hablar de una seguridad humana y no sólo de seguridad en términos realistas clásicos. En este caso, Kaldor amplia el concepto y agrega el término de -política- al concepto.

${ }^{33}$ Kaldor, Martin, Selchow 2007, p. 278.

${ }^{34}$ Ibíd., p. 279.

COLOMBIA: CONFLCTO IRREGULAR, DESPLAZAMIENTO INIERNO YSEGURIDAD HUMANA
} 
bien sean guerras o desastres naturales, en ambas situaciones son víctimas de inseguridad psicológica y material. ${ }^{35}$ Desde la década de 1970 , se ha presentado un incremento acelerado en el número de personas desplazadas que crece con cada conflicto. En el 2006, por ejemplo, más de mil civiles libaneses fueron asesinados y más de 400 mil fueron forzados a dejar sus hogares, de la misma manera, cientos de miles tuvieron que dejar Nueva Orleans como resultado de las inundaciones del Huracán Katrina ${ }^{36}$ y lógicamente miles más fueron desplazados en Sudán, Angola y Colombia, entre otros.

En relación con lo anterior, Kaldor, Martin y Selchow determinan unos principios de política de seguridad humana que resultan interesantes para el análisis de un conflicto particular como el colombiano:

\section{Figura 1}

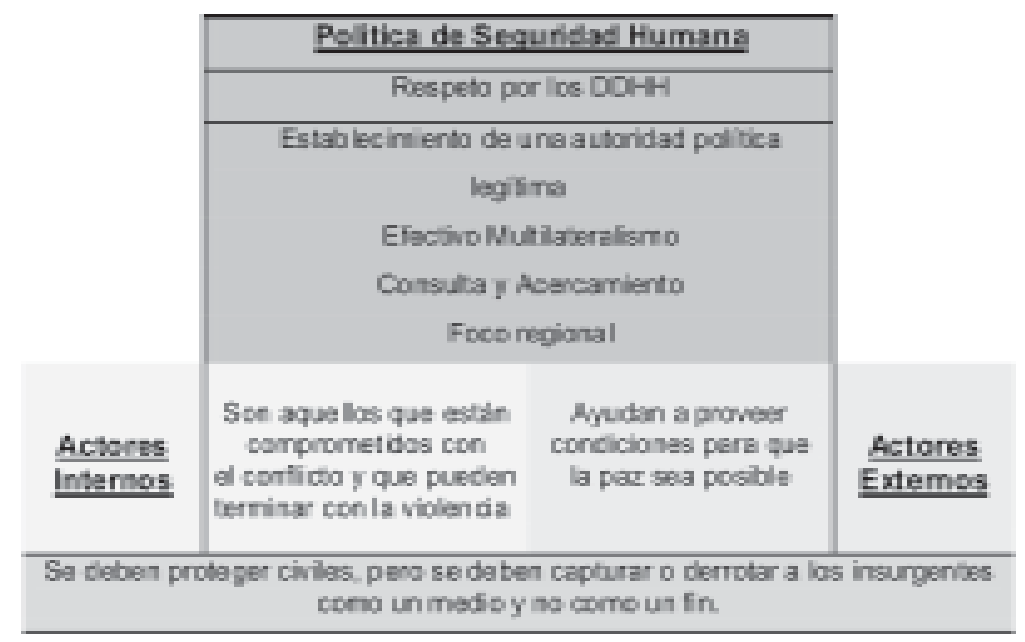

Fuente: Kaldor, Martin, Selchow 2007. Elaboración propia.

Como veremos más adelante, la mayoría de aspectos de la Figura 1 se cumplen de forma limitada al estudiar el caso del desplazamiento forzado interno en Colombia, el cual ha generado una migración masiva el campo hacia las grandes ciudades, debido a que la gente busca allí refugio, seguridad y ayuda, lo que ha generado el crecimiento de los cordones de miseria, y una demanda desmesurada de servicios público, sociales y vivienda. ${ }^{37}$

${ }^{35}$ Kaldor, Martin, Selchow enfatizan que no sólo en la guerra la seguridad humana presenta extrema vulnerabilidad, también consideran peligrosos los desastres tecnológicos: (Bophal - India, 1984), (Chernobyl - ex URSS, 1986) y, naturales (Tsunami - Sudeste asiático, 2004).

${ }^{36}$ Kaldor, Martin, Selchow 2007, p. 279.

${ }^{37}$ Sánchez 2006, p. 41. 
El trabajo de Sánchez, que si bien está focalizado en el desplazamiento que se vive en la ciudad de Mocoa, puede dar cuenta de las principales características y perfiles de estas víctimas en el país:

«En su gran mayoría la población asentada en Mocoa es campesina y en su lugar de origen se dedicaba a las labores agropecuarias y al trabajo de la tierra. También se destaca la presencia de maestros de escuelas rurales, funcionarios y concejales de gobiernos municipales, líderes y promotores comunitarios y algunas personas que trabajan en los comercios en los cascos urbanos de los municipios expulsores. Hay un porcentaje importante de población indígena que ha salido fundamentalmente de las zonas rurales más retiradas y de los resguardos existentes en los municipios, sin embargo, a pesar de haberse desplazado, aún continúan perteneciendo al cabildo indígena de origen».38

Los factores que generan el desplazamiento son los enfrentamientos entre guerrilla, paramilitares y grupos armados no identificados. También, un alto grado de violencia generalizada, y en ocasiones las fumigaciones de cultivos ilícitos. Debido al elevado costo de la tierra y vivienda, estas personas no pueden alquilar y mucho menos comprar una casa en los barrios tradicionales que cuentan con los servicio básicos. Por lo tanto, se ven obligados a ubicarse en terrenos de menor valor, en zonas de riesgo natural no aptas para urbanizar o, como último recurso, invaden las zonas rurales más alejadas del centro, en donde la oferta de servicios es baja o nula y, por su condición de informalidad, presenta grandes limitaciones para la legalización de la tierra por parte del Estado. ${ }^{39}$

En las grandes ciudades del país como Medellín, Cali, Barranquilla, Manizales Pereira, Armenia y Neiva, el número de desplazados crece cada año de forma dramática, según la organización CODHES, una entidad consultora en Derechos Humanos, a través de su Sistema de Información sobre Desplazamiento Forzado y Derechos Humanos SISDHES, informa que la cifra de desplazados en el país es de 2.853.445 en los últimos diez años. ${ }^{40}$ Deber tenerse en cuenta que las cifras en ocasiones varían de acuerdo a la entidad que las emite, y también a la naturaleza compleja de su consecución. Por ejemplo, la ACNUR en su página electrónica despliega un comunicado así: «Se estima que existen más de 3 millones de desplazados internos en el país». ${ }^{41}$ De la misma manera organismos internacionales como el Comité Internacional de la Cruz Roja (CICR), y think tanks como el International Crisis Group y, Human Right Watch se aproximan a esta cifra. ${ }^{42}$

38 Ibíd., p. 50.
${ }^{39}$ Ibíd., p. 58.

${ }^{40}$ CODHES 2007, p. 7. Para su realización CODHES contó con el apoyo de la Oficina en Colombia del Alto Comisionado de las Naciones Unidas para los Refugiados, el Consejo Noruego para los Refugiados, la Agencia Sueca de Cooperación Internacional para el Desarrollo ASDI y la Federación Luterana Mundial.

${ }^{41}$ ACNUR 2008. http://www.acnur.org/index.php

${ }^{42}$ Ver: www.icrc.orgwww y www.crisisgroup.org el material relativo está en los vínculos sobre Colombia y actualizado con relativa frecuencia, por lo tanto la cifra exacta es susceptible de variación.

COLOMBIA: CONFLCTO IRREGULAR, DESPLAZAMIENTO INTERNO Y SEGURIDAD HUMANA 
Luego de ver lo anterior, es claro que el fenómeno del desplazamiento es uno de los rasgos más relevantes del conflicto colombiano ante la opinión pública internacional. Se ha fortalecido como una estrategia de guerra macabra y efectiva con modalidades de copamiento de territorio, expulsión violenta de comunidades, redoblamiento con población ligada al actor armado dominante en la zona cercana y confinamiento. ${ }^{43}$ Vale la pena destacar que en ocasiones el desplazamiento ha sido en mucho casos una estrategia de supervivencia de la población en medio de la guerra, de resistencia civil, de huída de las zonas de conflicto, lo cual explica los intentos de cosmopolitanismo en medio de la guerra que enfatiza Kaldor, por ejemplo, en la ciudad de Tuzla en Bosnia Herzegovina o el noreste de Somalilandia en Sudáfrica. ${ }^{44}$

Existe cierto pesimismo ante el conflicto colombiano, debido a su complejidad y la circularidad de la violencia, que uno de los historiadores que más conocen sobre el tema denomina "orden y violencia». ${ }^{45}$ En otros trabajos se destaca que la superación definitiva del desplazamiento forzado sólo ocurrirá en el posconflicto. ${ }^{46}$ Por lo tanto, esta confluencia de variables complejas que intervienen en el conflicto, abren un espacio para el análisis y desarrollo de las estrategias que ha adoptado el gobierno colombiano y demás actores públicos, privados, locales, naciones e internacionales.

La ONU, por ejemplo, promulgó los principios rectores del desplazamiento con el propósito de establecer que los desplazados internos sean sujetos de derechos y, para recordar a los gobiernos las obligaciones que tienen con éstos. A pesar de que dichos principios no son vinculantes, al igual que los tratados, se fundamentan en el DIH, en la legislación de los Derechos Humanos y en el derecho internacional en materia de refugiados. Estos principios contemplan las necesidades específicas de los desplazados internos de todo el mundo, definen los derechos y garantías más adecuados para la protección de las personas contra el desplazamiento forzado, así como para su protección y asistencia durante el desplazamiento, retorno, reasentamiento y reintegración. ${ }^{47}$

Existen respuestas de instituciones internacionales al problema del desplazamiento, de acuerdo al documento de la ONU «E/CN.4/1998/53/Add.2» del 11 de febrero de 1998, en el anexo sobre «Principios rectores de los desplazamientos internos, ${ }^{48}$ introducción, alcance y finalidad, en el numeral exponen:

\footnotetext{
${ }^{43}$ Nuevo Arco Iris 2004, p. 11.

${ }^{44}$ Kaldor 1999, 2002, p. 277.

45 Pècaut citado en Gutiérrez y Stoller 2001.

${ }^{46}$ Nuevo Arco Iris 2004, p. 12.

47 Ibíd., p. 18.

${ }^{48}$ La Comisión de Derechos Humanos, designó a Francis M. Deng, diplomático sudanés, como representante para el tema de los desplazados internos, quien luego de un largo y complejo proceso presentó los Principios Rectores En Viena en 1988, en una conferencia a la que asistieron cincuenta expertos internacionales y que fue auspiciada por el gobierno de Austria.
} 
«A los efectos de estos principios se entiende por desplazado interno a las personas o grupos de personas que se han visto forzadas u obligadas a escapar o huir de su hogar o de su lugar de residencia habitual, para evitar los efectos de un conflicto armado, de situaciones de violencia generalizada, de violaciones de los derechos humanos o de catástrofes naturales o provocadas por el ser humano y que no han cruzado una frontera estatal internacionalmente reconocida». ${ }^{49}$

De la misma manera, hay respuestas de tipo nacional como la Ley 387 de 1997, la cual define un marco normativo para atender el problema, y establece en su artículo 1:

«Es desplazado toda persona que se ha visto forzada a migrar dentro del territorio nacional abandonando su localidad de residencia o actividades económicas habituales, porque su vida, su integridad física, su seguridad o libertad personales han sido vulneradas o se encuentran directamente amenazadas, con ocasión de cualquiera de las siguientes situaciones: conflicto armado interno, disturbios y tensiones interiores, violencia generalizada, violaciones masivas de los Derechos Humanos, infracciones al Derecho Internacional Humanitario u otras circunstancias emanadas de las situaciones anteriores que puedan alterar o alteren drásticamente el orden público».50

\section{CONCLUSIÓN}

Este trabajo muestra la evolución y complejización del conflicto interno colombiano. Hemos visto cómo los conflictos internos irregulares se han visto afectados por la globalización de la violencia organizada que identifica Kaldor. Y son los desplazados internos, un ejemplo crucial de esta problemática que está presente en varios conflictos del mundo, en donde se hace muy difícil identificar a los violentos en medio de la población civil. Por lo tanto, seguirá siendo un reto buscar una solución y salida justa al conflicto colombiano, incluso, con las herramientas que ofrece la política de la seguridad humana expuesta por Kaldor.

\section{BIBLIOGRAFÍA}

ACNUR 2008. Agencia par alas Refugiados de las Naciones Unidas. Disponible: (http://www.acnur.org/ index.php). Acceso: 28 de febrero de 2008.

CICR. Comité de la Cruz Roja Internacional. Convenios de Ginebra (1949) y Protocolos adicionales. Disponible: (http://www.icrc.org/web/spa/sitespa0.nsf/iwpList2/Info_resources:IHL_databases\#listanchor2) Acceso: 28 de febrero de 2008.

\footnotetext{
${ }^{49}$ ONU 1998.

${ }^{50}$ Colombia Ministerio del Interior y Justicia 1997.

COLOMBIA: CONFLICTO IRREGULAR, DESPLAZAMIENTO INTERNO Y SEGURIDAD HUMANA
} 
Cirera, Maria T. 2006. Los Desplazados Internos un Problema Internacional. Asociación para las Naciones Unidas - España. Masanes Gràfiques Barcelona.

CODHES. 2007. Boletín informativo de la Consultoría para los Derechos Humanos y el desplazamiento. Número 72, Bogotá, Colombia, 30 de noviembre de 2007.

Colombia Ministerio del Interior y Justicia 1997. Ley 387 de 1987. Disponible: (http:// www.mininteriorjusticia.gov.co/adminFiles/Ley\%20387\%20de\%201997.htm). Acceso 28 de febrero de 2008.

Corporación Nuevo Arco Iris. 2004. El Desplazamiento en Bogotá. Departamento Administrativo de Planeación Distrital.

Downes, Alexander. 2006. Desperate Times, Desperate Measures. The Causes of Civilian Victimization in War, en: International Security 30 (4):152-195.

Fearon James D., Laitin, David D. 2003. Ethnicity, Insurgency, and Civil War. The American Political Science Review 97 (1): 75-90.

Ferreyra Aleida. Segura, Renata (2000) Examining the Military in the Local Sphere: Colombia and Mexico, en: Latin American Perspectives, issue: Violence, Coercion, and Rights in the Americas 27 (2): 18-35.

Gutiérrez, Francisco. Stoller, Richard. 2001. The Courtroom and the Bivouac: Reflections on Law and Violence in Colombia. Colombia: The Forgotten War, en: Latin American Perspectives 28 (1):56-72.

Kalyvas, Stathis. 1999. Wanton and Cénseles? The Logia of Massacres in Algeria, en: Rationality and Society 20 (4):136-75.

Kaldor, Mary. 2001. Las Nuevas Guerras. Violencia Organizada en la Era Global. Barcelona. Tusquets.

Kaldor, Mary. Martin, Mary, Selchow Sabine. 2007. Human security: a new strategic narrative for Europe, en: International Affairs 83 (2): 273-288.

Nasi, Carlo. Ramírez, William. Lair, Eric. (2003) «Guerra Civil», en: Revista de Estudios Sociales 14: 119-126.

Nye, Joseph. 2003. La Paradoja del Poder Americano. Madrid. Taurus.

ONU. 1998. Report of the Representative of the Secretary-General, Mr. Francis M. Deng.Guiding Principles on Internal Displacement. Disponible: (http://www.unhchr.ch/huridocda/huridoca.nsf/(Symbol)/ E.CN.4.1998.53.Add.2.En?OpenDocument). Acceso: 28 de febrero de 2008. 
Pizarro, Eduardo y Bejarano, Ana Maria. 2003. "Colombia: A Failed State?», en: Harvard Review of Latin America, 2 (3).

Sánchez, Lina María. 2006. Impacto Urbano en el desplazamiento forzado en Mocoa. Bogotá. CINEP.

Shifter, Michael. 2000. (Director). Toward Greater Peace and Security in Colombia. Task Force Report. Council of Foreign Relations and Inter-Amercian Dialogue. New York.

USIP (United States Institute for Peace). 2006. Civil Society Under Siege in Colombia. Washington.

Valentino, Benjamín, Huth, Paul, Balch-Lyndsay, Dylan. «Draining the Sea»: Mass Killing and Guerrilla Warfare, en: International Organization 58 (2):375-407.

Vasquez, John A. 1993. The War Puzzle. Cambridge: Cambridge University Press.

COLOMBIA: CONFLCTO IRREGULAR, DESPLAZAMIENTO INTERNO Y SEGURIDAD HUMANA 